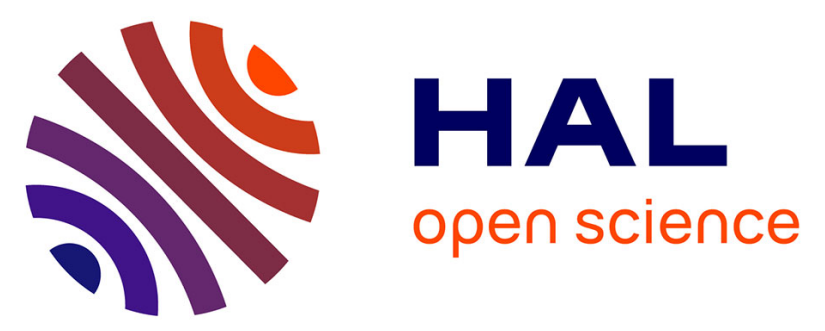

\title{
Novel Procedure for Assessment of Feasible Design Parameters of Dividing-Wall Columns: Application to Non-azeotropic Mixtures
}

Hassiba Benyounes, Khadidja Benyahia, Weifeng Shen, Vincent Gerbaud, Lichun Dong, Shun'An Wei

\section{To cite this version:}

Hassiba Benyounes, Khadidja Benyahia, Weifeng Shen, Vincent Gerbaud, Lichun Dong, et al.. Novel Procedure for Assessment of Feasible Design Parameters of Dividing-Wall Columns: Application to Non-azeotropic Mixtures. Industrial and engineering chemistry research, 2015, 54 (19), pp.5307-5318. 10.1021/ie5048576 . hal-01338271

\section{HAL Id: hal-01338271 \\ https://hal.science/hal-01338271}

Submitted on 28 Jun 2016

HAL is a multi-disciplinary open access archive for the deposit and dissemination of scientific research documents, whether they are published or not. The documents may come from teaching and research institutions in France or abroad, or from public or private research centers.
L'archive ouverte pluridisciplinaire HAL, est destinée au dépôt et à la diffusion de documents scientifiques de niveau recherche, publiés ou non, émanant des établissements d'enseignement et de recherche français ou étrangers, des laboratoires publics ou privés. 


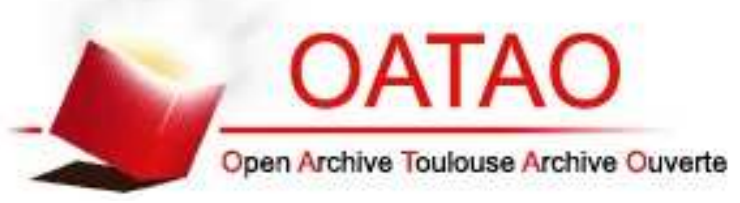

\section{Open Archive TOULOUSE Archive Ouverte (OATAO)}

OATAO is an open access repository that collects the work of Toulouse researchers and makes it freely available over the web where possible.

This is an author-deposited version published in : http://oatao.univ-toulouse.fr/ Eprints ID : 15856

To link to this article : DOI : 10.1021/ie5048576

URL : http://pubs.acs.org/doi/abs/10.1021/ie5048576

To cite this version : Benyounes, Hassiba and Benyahia, Khadidja and Shen, Weifeng and Gerbaud, Vincent and Dong, Lichun and Wei, Shun'an Novel Procedure for Assessment of Feasible Design Parameters of Dividing-Wall Columns: Application to Nonazeotropic Mixtures. (2015) Industrial \& Engineering Chemistry Research, vol. 54 ( ${ }^{\circ}$ 19). pp. 5307-5318. ISSN 0888-5885

Any correspondence concerning this service should be sent to the repository administrator: staff-oatao@ listes-diff.inp-toulouse.fr 


\title{
Novel Procedure for Assessment of Feasible Design Parameters of Dividing-Wall Columns: Application to Non-azeotropic Mixtures
}

\author{
Hassiba Benyounes, ${ }^{\dagger}$ Khadidja Benyahia, ${ }^{\dagger}$ Weifeng Shen, ${ }^{*}, \S, \|, \perp$ Vincent Gerbaud, ${ }^{\|, \perp}$ Lichun Dong, ${ }^{\ddagger}, \S$ \\ and Shun'an Wei*, ${ }^{*}, \S$ \\ †Laboratoire de Chimie Physique des Matériaux, Catalyse et Environnement, Université des Sciences et de la Technologie Oran \\ (UST Oran), Oran, Algeria \\ ${ }^{\ddagger}$ School of Chemistry and Chemical Engineering, Chongqing University, Chongqing 400044, China \\ ${ }^{\S}$ Key Laboratory of Low-grade Energy Utilization Technologies \& Systems of the Ministry of Education, Chongqing University, \\ Chongqing 400044, China \\ "Université de Toulouse, INP, UPS, LGC (Laboratoire de Génie Chimique), 4 allée Emile Monso, F-31432 Toulouse Cedex 04, \\ France. \\ ${ }^{\perp}$ CNRS, LGC (Laboratoire de Génie Chimique), F-31432 Toulouse Cedex 04, France
}

\begin{abstract}
Dividing wall columns (DWCs), as a subset of fully thermally coupled distillation systems (FTCDS), is considered as one of most appealing distillation technologies to the chemical industry, because it can bring about substantial reduction in the capital investment, as well as savings in the operating costs. This study targets on how to improve the energy efficiency of DWCs by achieving their well-designed feasible parameters. Two methods are applied to study the effect of liquid and vapor split ratios including a shortcut method and a method of systematic calculations by using differential equation profiles. In the latter approach, differential composition profiles in each column section are obtained by considering feasible key design parameters. The finding of pinch points for each section profiles allowed determining the limiting values of the operating parameters. The intersections of these profiles are used to get well-designed feasible parameters of the liquid and vapor split ratios in an attempt to obtain the desired purities of the top, bottom, and side-stream products. The obtained parameters are validated by rigorous simulations. Three types of case studies involve the separation of hydrocarbons $(n$-pentane, $n$-hexane, $n$ heptane), aromatics (benzene, toluene, $p$-xylene), and alcohols (ethanol, propanol, butanol).
\end{abstract}

\section{INTRODUCTION}

Distillation columns are used for $\sim 95 \%$ of liquid separations and the energy use from this process accounts for an estimated $3 \%$ of world's energy consumption. ${ }^{1}$ Distillation is the most commonly used separation technique in the chemical and petrochemical process industries but, at the same time, also is the most energy intensive operation unit. To overcome this problem, several heat-integrated and fully thermally coupled distillation systems (FTCDS, also called Petlyuk columns) were studied, and it has been proved that thermally coupled configurations, such as dividing distillation columns (DWCs), are promising energy alternative solutions. The theoretical studies have shown that DWCs can achieve $~ 30 \%$ energy and capital cost savings, compared to conventional distillation systems. Any reduction of energy consumption will not only bring economic benefits but also environmental benefits, in terms of reduced usage of fossil fuels and its associated emissions. $^{2,3}$

Thermally coupled arrangements are realized by setting up two-way vapor/liquid flows between different columns of the simple column configurations. ${ }^{4}$ Reported studies ${ }^{5-18}$ reveal that Petlyuk columns provide maximum energy reduction in columns, and in most cases, it is implemented in the form of a dividing-wall column (DWC) in which both columns are located in a single shell. This reduces not only the energy consumption but also space and investment requirements, compared to the conventional column system.

The DWC has been known for several decades, since a patent submitted by Wright. ${ }^{19}$ Petlyuket al. ${ }^{20}$ introduced the thermal coupling for separating ternary mixtures and presented a fully thermally coupled configuration-Petlyuk column. Thermally coupled distillation arrangements offer direct coupling between the prefractionator and the main column, which reduce mixing losses and also minimize the energy requirements for a specified separation. Amminudin et al. ${ }^{21}$ developed a semirigorous method for the initial design of FTCDS. In their study, the FTCDS was divided into two separate columns to eliminate interlinking and obtain an optimal design that could be confirmed through rigorous simulation. Fidkowski and Krolikowski ${ }^{22}$ established that, among all the options for a three-product system, the Petlyuk system requires the least energy. This key advantage is also applicable for a DWC, which has the minimum vapor flow rate for the particular separation, compared to the conventional system. Triantafyllou and Smith, ${ }^{23}$ and Agrawal and Fidkow$\mathrm{ski}^{24}$ showed that, for a mixture of three components, the 

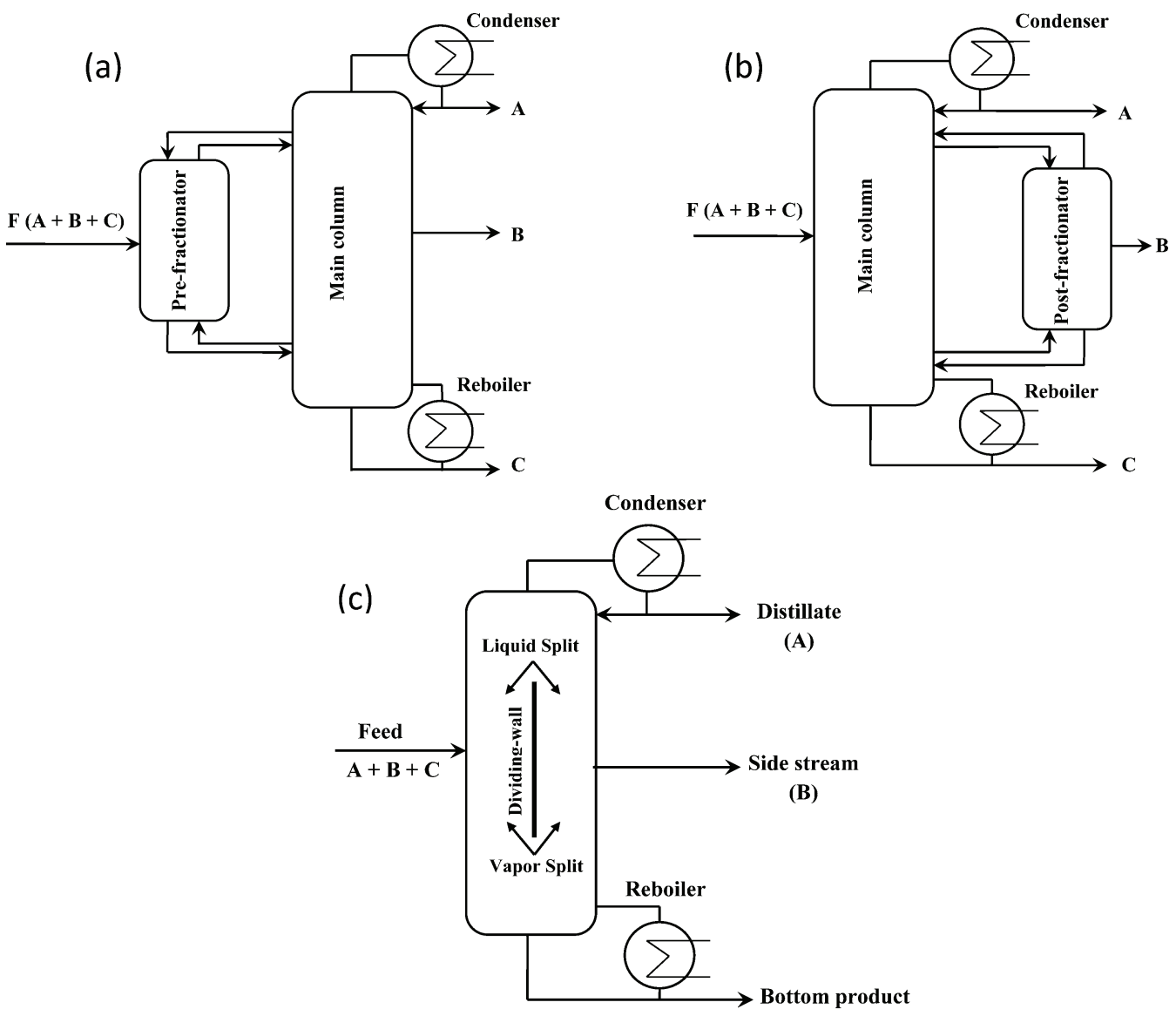

(C)

Figure 1. Fully thermally coupled distillation columns: (a) with a prefractionator, (b) with a postfractionator, and (c) with a dividing-wall column (DWC).

DWC reduces the total vapor flow by $10 \%-50 \%$, compared to conventional systems using direct and indirect sequences.

Reduction in vapor flow contributes to lower duties of reboiler and condenser and, consequently, capital and operating costs. Furthermore, DWC uses only one reboiler and one condenser, compared to a conventional two-column system with two reboilers and two condensers. This would be beneficial to the savings in capital costs, as well as operating costs. Simulations and experimental studies of Abdul Mutalib and $S_{\text {mith }}{ }^{25,26}$ demonstrate that the DWC can be operated successfully.

Lee et al. ${ }^{27}$ proposed a design method from which internal sections of the column system are divided into six separate sections and matched to the sloppy arrangement with three conventional simple columns. Uwitonze et al. ${ }^{28,29}$ introduced a new design method based on approximate group method. The proposed method uses the group methods for the design of each column section, and they focus on employing an approximate method that relates the compositions of multicomponent vapor and liquid streams inside the column section and streams leaving the column to compute the number of stages. This design method gives near-optimal values of all important design variables, mainly the total number of trays in all column sections.

Design of DWCs has been studied in the open literature using basic equations and using commercial simulators. Investigators ${ }^{30-34}$ generally use Fenske-Underwood-Gilliland (FUG) equations as part of the shortcut method for initialization, followed by a rigorous simulation with simulators Aspen HYSYS. Shortcut methods have been proposed for the design of Petlyuk and divided-wall columns, ${ }^{27-34}$ which can be used to quickly evaluate the applicability of a Petlyuk system for a given separation problem. ${ }^{35}$ Alternative structures to the Petlyuk column have been developed by changing or eliminating interconnection flows. ${ }^{36}$ Sotudeh and Shahraki ${ }^{30}$ proposed another shortcut method. In their method, the compositions in the upper and lower zones of the prefractionator are design variables. The total number of trays of each section in the main column can be calculated, and the minimum total number of trays in the main column is obtained by manipulating the variables. Only the number of trays in the side section is calculated, and the total number of trays in the prefractionator is set to be the same as in the side section. However, this method may not always work, because we cannot be certain that the prefractionator will have enough trays. Also, they did not explain how exactly to decide the vapor and liquid split ratio. Chu et al. ${ }^{34}$ developed a novel design method that can be applied to all three types of DWCs. The method allows for the determination of near-optimal values of all important design variables, including the reflux ratio, the total number of trays in all column sections, and values of the liquid and vapor split ratios. However, it suggests iterative adjustments in the design of the sections of main column, which makes the method somewhat tedious.

In this contribution, we developed a novel shortcut method that combined the Fenske, Underwood, Gilliland, and 


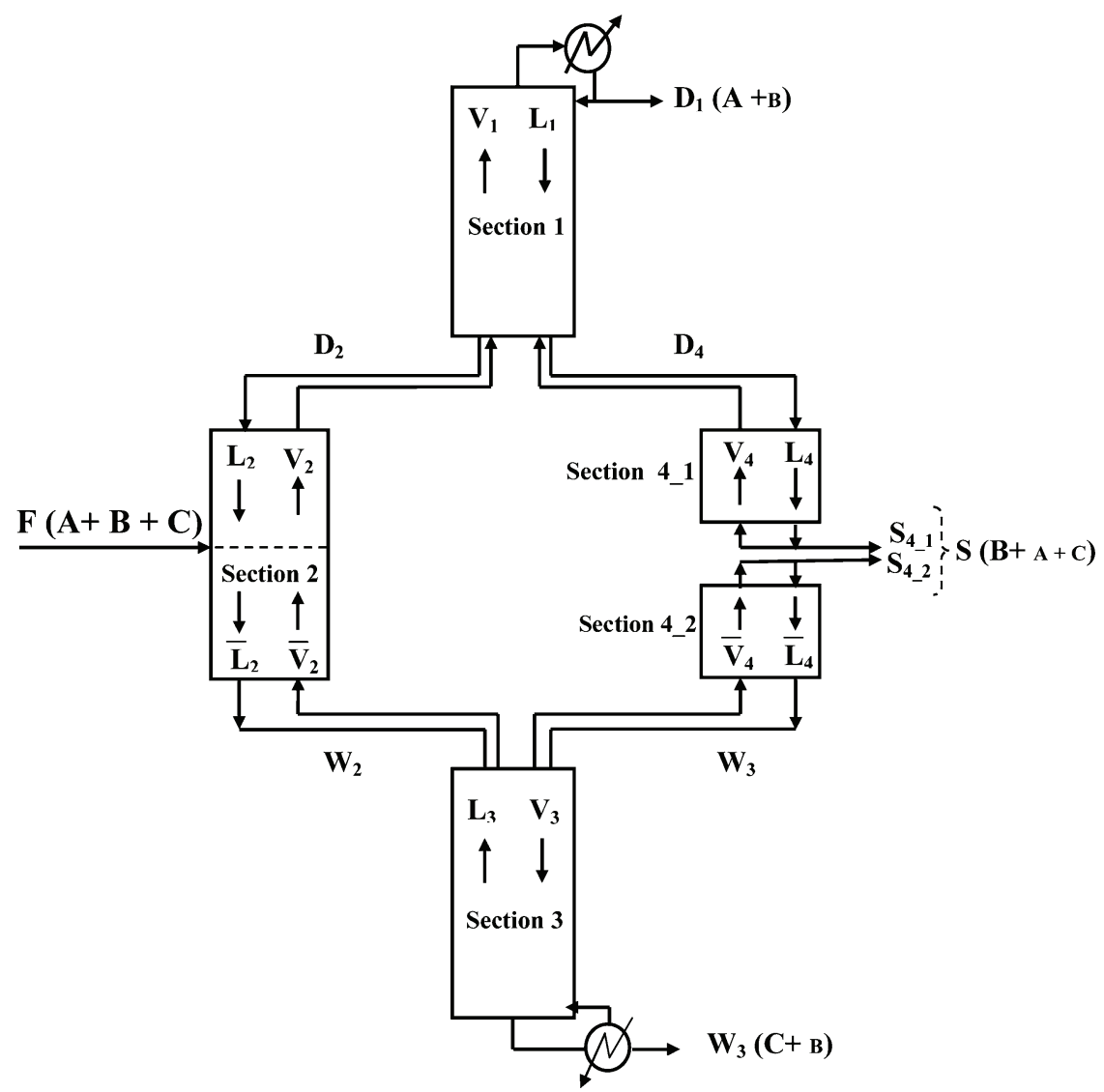

Figure 2. Model applied for the design of a three-product DWC. ${ }^{34}$

Kirkbride equations. Composition profiles of different sections (e.g., rectifying, prefractionator, and stripping) of DWCs are derived following the differential model; the composition profiles are established to assess feasible design parameters (e.g., reflux ratio, interlinking vapor and liquid streams, and reboil ratio). This work attempts to study the feasibility of DWC by introducing a new design method based on the calculation of the composition profiles, which allows one to define the key operating parameters necessary to make the process feasible. Three types of illustrative cases are investigated in this study: hydrocarbon mixture separation (pentane-hexane-heptane), aromatic mixture (benzenetoluene-xylene), and alcohol mixture (ethanol-propanolbutanol). The rigorous simulations are performed to validate the obtained parameters using shortcut method and systematic calculation based on differential equations to determine the well-designed parameters of fully thermally coupled distillation columns.

\section{METHODOLOGY}

2.1. Establishment of Design Models of DWCs. The modern energy-integration technologies for multicomponent distillation separations are mostly based on the Petlyuk configurations. DWC (Figure 1) is a practical implementation of the Petlyuk setup, in which the prefractionator and the main column are built in a single shell but separated by a vertical wall inside the column. ${ }^{7,37,38}$ The prefractionator (feed side of the column) performs the preferred separation between lightest and heaviest products, driving them toward the top and bottom, respectively. The objective of the main column (sidestream section) is to obtain a high-purity side-stream product of a middle boiling component. These features allow the DWC to achieve average $25 \%-30 \%$ of energy savings by avoiding remixing effects when it has been well-controlled. ${ }^{11,14}$ Besides the energy savings, compared to the conventional distillation sequences, DWC also provides a lower capital expenditure and a smaller plant footprint. The process flowsheets of DWC are illustrated in Figure 1. Figures 1a and $1 \mathrm{~b}$ represent schematic diagrams of thermally coupled distillation column with a prefractionator and a postfractionator, respectively, where liquid and vapor are distributed across the two column sections. Figure 1c provides the typical design structure of the DWCs. The light component recovered at the top is denoted as " $A$ ", the middle boiling component recovered in the sidestream is defined as " $\mathrm{B}$ ", and the heavy component recovered as the bottom product is denoted as " $\mathrm{C}$ ".

We assumed that component $\mathrm{B}$ is distributed to three product sections of the FTCD column, while a small amount remains at the top and bottom. The relative volatility of each component is considered constant from top to bottom throughout a symmetrical column. The net flows model is interpreted in Figure 2. ${ }^{34}$ Referring to this net flow diagram, the material balance equations for modeling the thermally coupled column are illustrated as follows:

Balance on component A:

$$
F Z_{\mathrm{A}}=D_{1} x_{\mathrm{AD} 1}+S x_{\mathrm{AS}}+W_{3} x_{\mathrm{AW} 3}
$$

Balance on component B:

$$
F Z_{\mathrm{B}}=D_{1} x_{\mathrm{BD} 1}+S x_{\mathrm{BS}}+W_{3} x_{\mathrm{BW} 3}
$$


Balance on component C:

$$
F Z_{\mathrm{C}}=D_{1} x_{\mathrm{CD} 1}+S x_{\mathrm{CS}}+W_{3} x_{\mathrm{CW} 3}
$$

The column is divided into five sections: section 2 is equivalent to a prefractionator column; sections 1 and 3 correspond to the rectifying section and the stripping section of the main column, respectively; sections 41 and 42 represent the upper and lower section of the right side of the DWCs, respectively.

Therefore, the net flow of component $\mathrm{C}$ at the top of section 2 is assumed to be equal to the flow of component $C$ in the side draw. Similarly, the net flow of component A at the bottom of section 2 is equal to the flow of component $\mathrm{A}$ in the side draw. The component $\mathrm{B}$ is distributed to the top and bottom products of section 2 (prefractionator). $\beta$ is defined as the fraction of $\mathrm{B}$ sent to the top of prefractionator, and it is calculated by eq $4 .{ }^{34}$

$$
\beta=\frac{x_{\mathrm{BD} 2} D_{2}}{F z_{\mathrm{B}}}
$$

The top and bottom product net flows of each section are obtained using the following balance equations:

$$
\begin{aligned}
& D_{2}=F Z_{\mathrm{A}}+\beta F z_{\mathrm{B}}+S\left(x_{\mathrm{CS}}-x_{\mathrm{AS}}\right) \\
& W_{2}=F-D_{2} \\
& W_{4}=W_{2}-W_{3}
\end{aligned}
$$

The given assumptions allow one to determine (approximately) the composition at key points in the column. The compositions of $D_{2}, W_{2}, S_{41}$ and $S_{42}$ are obtained by the mass balance at given feed flow rate $(F)$, feed compositions $\left(x_{\mathrm{AF}}, x_{\mathrm{BF}}\right.$, and $\left.x_{\mathrm{CF}}\right)$, and product purities $\left(x_{\mathrm{D} 1}, x_{\mathrm{S}}\right.$, and $\left.x_{\mathrm{W} 3}\right)$. In this work, we consider a column with theoretical stages, such that, to follow the assumption given in the shortcut method for the design of DWC, in this respect, the phases leaving each of its plates are mutually in thermodynamic phase equilibrium.

2.2. Design Procedure for DWCs Using a Shortcut Method. Based on the Fenske, Underwood, Gilliland, and Kirkbride equations, ${ }^{39-42}$ a shortcut method is applied in this study. The relative volatility of each component is assumed to be constant throughout the column. The compositions of the top and bottom products of each section are required for calculation of total trays number. Also, the thermal feed state $q$ and relative volatility $\alpha_{i j}$ of each component are necessary for calculation of the minimum vapor flow using Underwood equations (i.e., eqs 9 and 10), which relies on assumptions of constant molar flow rate and constant relative volatility. Again, the notation is demonstrated in Figure 2.

The value of $\beta$ is required for calculation of net flows and compositions of streams at the top and bottom of prefractionator $D_{2}$ and $W_{2}$ (see eqs 5 and 6). This variable is defined when the condition in eq 8 is satisfied.

$$
V_{\min , 4 \_1}=V_{\min , 4 \_2}
$$

The minimum vapor flow is calculated on the basis of the given roots limited by the values of the relative volatilities $\alpha_{\mathrm{A}}$, $\alpha_{\mathrm{B}}$, and $\alpha_{\mathrm{C}}$, the maximum one is chosen (see eqs 9 and 10). The liquid $L_{\min , k}$ and vapor $V_{\min , k}$ flows are combined to form distillate flow $D_{k}$ (see eq 11).

$$
1-q=\sum \frac{\alpha_{i}, \mathrm{z}_{i}}{\alpha_{i}-\theta} \quad i=\{\mathrm{A}, \mathrm{B}, \mathrm{C}\}
$$

where $\alpha_{\mathrm{A}}>\theta_{1}>\alpha_{\mathrm{B}}>\theta_{2}>\alpha_{\mathrm{C}}, \theta_{1}$, and $\theta_{2}$ are the roots of the Underwood equation. The minimum vapor flow rates for four sections can be obtained using eq 12:

$$
\begin{aligned}
& V_{\min , k}=\sum \frac{\alpha_{i}, x_{i} D_{k}}{\alpha_{i}-\theta} \quad k=1,2,3,4 \text { (section number) } \\
& L_{\min , k}=V_{\min , k}-D_{k}
\end{aligned}
$$

For section 2, the minimum theoretical tray number is calculated using the Fenske equation (i.e., eq 12); three $N_{\text {min }}$ values of ternary mixture are obtained, and we choose the maximum value. For others sections, sections 1 and 41 are combined in a similar fashion, for the purpose of calculating the minimum total number of trays (see eq 13), and same is true for sections 3 and $4 \_2$ (using eq 14).

$$
\begin{aligned}
& N_{\text {min }, 2}=\frac{\ln \left(Z_{i} / Z_{j}\right)_{D_{2}}\left(Z_{j} / Z_{i}\right)_{W_{2}}}{\ln \alpha_{i j}} \quad i, j=\{\mathrm{A}, \mathrm{B}, \mathrm{C}\} \\
& N_{\min , 1}+N_{\min , 4 \_1}=\frac{\ln \left(Z_{i} / Z_{j}\right)_{D_{1}}\left(Z_{j} / Z_{i}\right)_{W_{4_{-} 1}}}{\ln \alpha_{i j}} \\
& i, j=\{\mathrm{A}, \mathrm{B}\} \\
& N_{\min , 3}+N_{\min , 4 \_2}=\frac{\ln \left(Z_{i} / Z_{j}\right)_{D_{4_{-}-2}}\left(Z_{j} / Z_{i}\right)_{W_{3}}}{\ln \alpha_{i j}} \\
& i, j=\{\mathrm{B}, \mathrm{C}\}
\end{aligned}
$$

The internal reflux ratio change along with the changes in liquid split ratio $S_{\mathrm{L}}$ and vapor split ratio $S_{\mathrm{V}} \cdot S_{\mathrm{L}}$ and $S_{\mathrm{V}}$ are defined as

$$
\begin{aligned}
& S_{\mathrm{L}}=\frac{L_{2}}{L_{1}} \\
& S_{\mathrm{V}}=\frac{V_{2}}{V_{3}}
\end{aligned}
$$

We note that $\beta, N_{\min , 1} / N_{\min , 4 \_1}, N_{\min , 3} / N_{\min , 4 \_2}, S_{\mathrm{L}}$, and $S_{\mathrm{V}}$ are the degrees of freedom of the shortcut design procedure for DWC. The minimum reflux ratios and reflux ratios are first defined; the total number of stages then is calculated for each section using Gilliland correlation (i.e., eq 17). The two degrees of freedom, $N_{\min , 1} / N_{\min , 4}{ }_{1}$ and $N_{\min , 3} / N_{\min , 4}$ 2, are defined when the Kirkbride equations (i.e., eqs 18 and 19) are satisfied. ${ }^{34}$

$$
\begin{aligned}
& \frac{N-N_{\min }}{N+1}=0.75\left[1-\left(\frac{R-R_{\min }}{R+1}\right)^{0.5688}\right] \\
& \frac{N_{1}}{N_{4 \_1}}=\left[\frac{D_{1}}{S_{4 \_1}} \times \frac{x_{\mathrm{AD} 1} D_{1}}{x_{\mathrm{BS} 4 \_1} S_{4 \_1}}\right]^{0.206} \\
& \frac{N_{4 \_2}}{N_{3}}=\left[\frac{S_{4 \_2}}{W_{3}} \times \frac{x_{\mathrm{BS} 4 \_2} S_{4 \_2}}{x_{\mathrm{CW} 3} W_{3}}\right]^{0.206}
\end{aligned}
$$

The shortcut design procedure for DWC of non-azeotropic mixture is illustrated in Figure 3. To get the design parameters, a value of $\beta$, needed to calculate the minimum vapor flow rate at each section, is set using above given equations. We then 


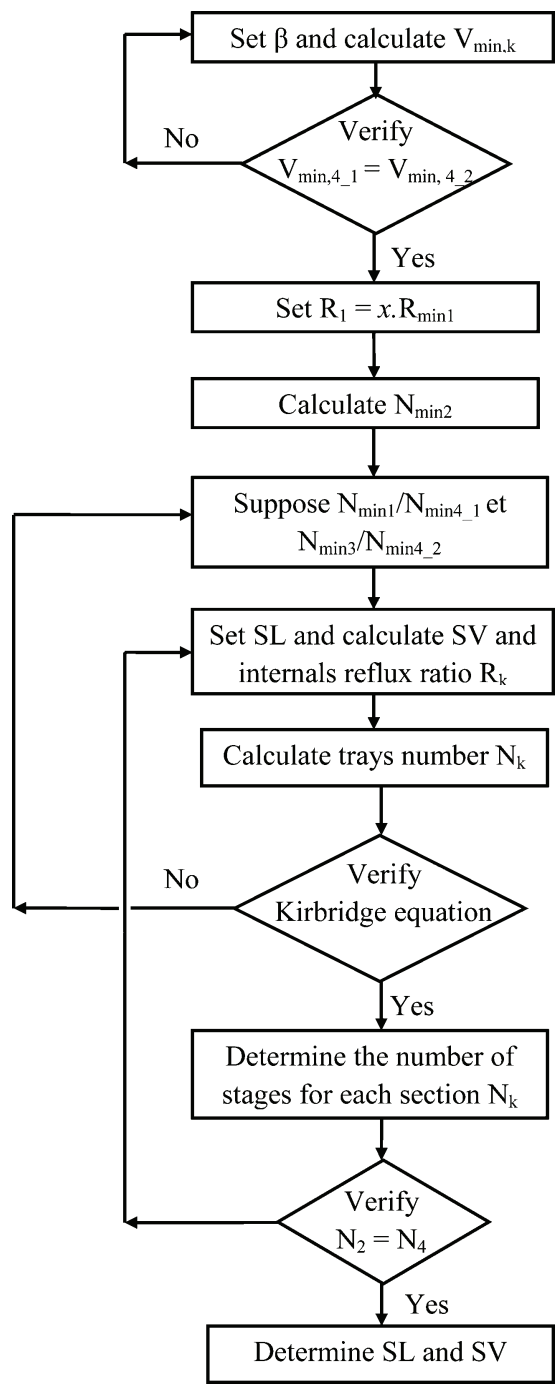

Figure 3. Shortcut design procedure for non-azeotropic mixtures in a DWC column.

choose a value of $\beta$ when the equal minimum vapor flows of sections 4_1 and 4_2 could be achieved. The estimated minimum vapor flows allow one to calculate the minimum reflux ratio at each section of the column and the minimum total number of trays. We set the reflux ratio at the condenser of the main column and calculate the internal reflux ratio with every given value of liquid split ratio $S_{\mathrm{L}}$. Iterative calculations on $S_{\mathrm{L}}$ are performed until the Kirkbride equation is satisfied, and then the total number of stages is determined.

2.3. Assessment of Feasible Design Parameters of the DWC Using Profile Models. To assess the feasible parameters of DWC for separation of ternary non-azeotropic mixture, in this section, we develop the profiles models for different sections of DWC, based on the differential equation of Lelkes. ${ }^{43-45}$ The computing of composition profiles approach has been proven to be very efficient in assessing feasible design parameters of nonideal mixtures and separations using extractive distillation. ${ }^{46-48}$ The differential model is based on the following simplifying assumptions: (i) theoretical plates, (ii) saturated liquid feed, and (iii) constant molar flow rate ratio in the four respective DWC sections. The computing of section composition profiles allows checking whether they intersect each other. The process is feasible if the composition profile connects the top and bottom compositions.

The investigated DWC, equivalent to fully thermally coupled distillation column (FTCD), can be divided into four sections as in Figure 2. Each section of FTCD is described by profile equations: rectifying profile is the function of reflux ratio, the prefractionator profiles are functions of the liquid and vapor split ratio, and the stripping profile is a function of the reboil ratio. We derived the following profile equations of each section:

Section 2_1, the prefractionator profile above the feed stream:

$$
\frac{\mathrm{d} x}{\mathrm{~d} h}=\frac{S_{\mathrm{V}} V_{3}}{S_{\mathrm{L}} R_{1} D_{1}}\left[\left(\frac{S_{\mathrm{L}} R_{1} D_{1}}{S_{\mathrm{V}} V_{3}}\right) x+\left(\frac{D_{2}}{S_{\mathrm{V}} V_{3}}\right) x_{D_{2}}-y^{*}\right]
$$

Section 2_2, the prefractionator profile below the feed stream:

$$
\frac{\mathrm{d} x}{\mathrm{~d} h}=\frac{S_{\mathrm{V}} V_{3}}{S_{\mathrm{L}} R_{1} D_{1}+F}\left[\left(\frac{S_{\mathrm{L}} R_{1} D_{1}+F}{S_{\mathrm{V}} V_{3}}\right) x-\frac{W_{2} x_{W_{2}}}{S_{\mathrm{V}} V_{3}}-y^{*}\right]
$$

The main column can be described by the following four composition profiles:

Section 1 , the rectifying profile:

$$
\frac{\mathrm{d} x}{\mathrm{~d} h}=\frac{R_{1}+1}{R_{1}}\left[\left(\frac{R_{1}}{R_{1}+1}\right) x+\frac{x_{D_{1}}}{R_{1}+1}-y^{*}\right]
$$

Section 3, the stripping profile:

$$
\frac{\mathrm{d} x}{\mathrm{~d} h}=\frac{\varphi}{\varphi+1}\left[\left(1+\frac{1}{\varphi}\right) x-\left(\frac{1}{\varphi}\right) x_{W_{3}}-y^{*}\right]
$$

Section 4_1, the middle section profile above the side stream:

$$
\begin{aligned}
\frac{\mathrm{d} x}{\mathrm{~d} h}= & \frac{\left(1-S_{\mathrm{V}}\right) V_{3}}{\left(1-S_{\mathrm{L}}\right) R_{1} D_{1}}\left[\left(\frac{\left(1-S_{\mathrm{L}}\right) R_{1} D_{1}}{\left(1-S_{\mathrm{V}}\right) V_{3}}\right) x+\frac{D_{4} x_{D_{4}}}{\left(1-S_{\mathrm{V}}\right) V_{3}}\right. \\
& \left.-y^{*}\right]
\end{aligned}
$$

Section 4_2, the middle section profile below the side stream:

$$
\begin{aligned}
\frac{\mathrm{d} x}{\mathrm{~d} h}= & \frac{\left(1-S_{\mathrm{V}}\right) V_{3}}{\left(1-S_{\mathrm{L}}\right) R_{1} D_{1}-S} \\
& \times\left\{\left[\frac{\left(1-S_{\mathrm{L}}\right) R_{1} D_{1}-S}{\left(1-S_{\mathrm{V}}\right) V_{3}}\right] x-\frac{W_{4} x_{W_{4}}}{\left(1-S_{\mathrm{V}}\right) V_{3}}-y^{*}\right\}
\end{aligned}
$$

The profile equations model is applied for the design DWC (see Figure 2), the developed equations (eqs 20 and 21) are used to describe the prefractionator (section 2), and eqs 24 and 25 are applied to interpret the middle section of the main column (section 4). The section profiles are functions of the liquid and vapor split ratios $\left(S_{\mathrm{L}}, S_{\mathrm{V}}\right)$, the vapor flow rate at the reboiler $\left(V_{3}\right)$, and the reflux ratio $\left(R_{1}\right)$ of the main column. The composition profiles are calculated with the aid of Simulis thermodynamic1.4.10 software, and the rigorous simulation is carried out using ProSimPlus 3.3 software. ${ }^{49}$ 
Table 1. Feed Composition and Physical Properties of Three Cases of Illustrated Mixtures

\begin{tabular}{|c|c|c|c|c|c|c|c|}
\hline \multicolumn{2}{|c|}{ case study } & \multirow{2}{*}{$\begin{array}{c}\text { feed composition, } z_{i} \\
0.4\end{array}$} & \multirow{2}{*}{$\begin{array}{c}\text { relative volatility, } \alpha_{i j} \\
7.9272\end{array}$} & \multirow{2}{*}{$\begin{array}{c}\text { boiling temperature }\left({ }^{\circ} \mathrm{C}\right) \\
36.06\end{array}$} & \multirow{2}{*}{$\begin{array}{l}\text { feed flow rate }(\mathrm{kmol} / \mathrm{h}) \\
45\end{array}$} & \multirow{2}{*}{$\begin{array}{c}\text { pressure (bar) } \\
1.49\end{array}$} & \multirow{2}{*}{$\begin{array}{c}\mathrm{ESI}^{a} \\
1.0202\end{array}$} \\
\hline Case 1 & pentane & & & & & & \\
\hline & hexane & 0.2 & 2.7875 & 68.73 & & & \\
\hline & heptane & 0.4 & 1 & 98.43 & & & \\
\hline \multirow[t]{3}{*}{ Case 2} & benzene & 0.3 & 5.4100 & 80.09 & 3600 & 0.37 & 1.0315 \\
\hline & toluene & 0.3 & 2.2901 & 110.65 & & & \\
\hline & xylene & 0.4 & 1 & 138.36 & & & \\
\hline \multirow[t]{3}{*}{ Case 3} & ethanol & 0.2 & 4.5310 & 78.25 & 100 & 1.00 & 0.9224 \\
\hline & propanol & 0.6 & 2.2163 & 97.15 & & & \\
\hline & butanol & 0.2 & 1 & 117.75 & & & \\
\hline
\end{tabular}

Table 2. Specifications of DWC Column for Three Case Studies

\begin{tabular}{|c|c|c|c|}
\hline & Case 1 & Case 2 & Case 3 \\
\hline & pentane/hexane/heptane & benzene/toluene/xylene & ethanol/propanol/butanol \\
\hline \multicolumn{4}{|l|}{ Distillate } \\
\hline$D_{1}(\mathrm{kmol} / \mathrm{h})$ & 18 & 1090,8 & 20 \\
\hline$x_{\mathrm{D} 1}$ (mole fraction) & $0.9834 / 0.0166 / 0$ & $0.9867 / 0.0133 / 0$ & $0.956 / 0.044 / 0$ \\
\hline \multicolumn{4}{|l|}{ Sidestream } \\
\hline$S(\mathrm{kmol} / \mathrm{h})$ & 9 & 1065.6 & 60 \\
\hline$x_{\mathrm{S}}($ mole fraction $)$ & $0.0332 / 0.9635 / 0.0033$ & $0.0035 / 0.9585 / 0.0380$ & $0.015 / 0.977 / 0.008$ \\
\hline \multicolumn{4}{|l|}{ Bottom Product } \\
\hline$W_{3}(\mathrm{kmol} / \mathrm{h})$ & 18 & 1443.6 & 20 \\
\hline$x_{\mathrm{W} 3}$ (mole fraction) & $0 / 0.0017 / 0.9983$ & $0 / 0.0306 / 0.9694$ & $0 / 0.025 / 0.975$ \\
\hline \multicolumn{4}{|l|}{ Vapor } \\
\hline$V_{3}(\mathrm{kmol} / \mathrm{h})$ & 56 & 3881.6 & 174.7 \\
\hline
\end{tabular}

In this study, a shortcut method based on the FenskeUnderwood-Gilliland-Kirkbride equations is first employed in order to calculate the preliminary operating parameters of the DWC configuration, the obtained parameters were then applied to assess their feasibility and determine the composition of the interlinking liquid and vapor streams and the composition of the feed tray. Finally, the obtained set of parameters (reflux ratio, liquid split, vapor split, total number of stages, stage locations of feed stream, side stream, and liquid and vapor interlinking streams) was used to initialize the rigorous simulation of DWCs. The numbers of stages of the main column and the prefractionator, as well as the liquid and vapor splits, have been adjusted to achieve high product purity via rigorous steady-state simulation.

\section{APPLICATION OF THE PROPOSED DESIGN METHOD}

Three categories of ternary non-azeotropic mixtures are investigated to illustrate the effectiveness of the proposed design method. For the sake of simplicity, three component abbreviations are used: A represents the lightest component, B represents the middle component, and $\mathrm{C}$ is the heaviest component. The three case studies involve the separation of hydrocarbons (where $\mathrm{A}=n$-pentane, $\mathrm{B}=n$-hexane, and $\mathrm{C}=n$ heptane), aromatics (where $\mathrm{A}=$ benzene, $\mathrm{B}=$ toluene, and $\mathrm{C}=$ $p$-xylene), and alcohols (where $\mathrm{A}=$ ethanol, $\mathrm{B}=$ propanol, and $\mathrm{C}=$ butanol). The degree of difficulty for the separation is characterized by the ease of separation index (ESI), as defined in eq $26^{50}$

$$
\mathrm{ESI}=\frac{\alpha_{\mathrm{AB}}}{\alpha_{\mathrm{BC}}}
$$

For the feed case where ESI $>1$, the ease of splitting A from $B$ is easier than splitting B from C. For the feed case where ESI $<1$, the ease of splitting A from B is more difficult than splitting $B$ from C. In this study, we intend to study different mixtures with close ESI in order to compare their performances. For the selected case studies, the compositions of feed stream have been chosen in such way as to have close ESI values for mixtures that belong to different chemical families (i.e., hydrocarbon, aromatics, and alcohol mixtures).

The Modified UNIFAC Dortmund is used to predict the vapor-liquid equilibrium (VLE) for mixtures of alcohol (ethanol-propanol-butanol) and aromatics (benzene-toluene-xylene) in the simulations. The binary parameters of NRTL and UNIQUAC models for these two mixtures are not complete, and both mixtures are not common mixtures lacking adequate experimental data to regress. Since the PengRobinson equation of state could reliably predict hydrocarbon mixtures, the Peng-Robinson equation is chosen for the pentane-hexane-heptane hydrocarbon mixture. Table 1 summarizes the feed specifications and thermodynamic properties of three mixture cases.

\section{RESULTS AND DISCUSSION}

4.1. Preliminary Design Parameters Using a Shortcut Method. In this section, the preliminary designs of the columns were performed based on a proposed shortcut method. The DWC specifications for three illustrated cases are calculated by mass balance and given in Table 2 . The 
shortcut design method provides information on the feed stage and the total number of stages of prefractionator, total number of stages of the main column, interlinking stages, and interlinking liquid and vapor flow.

The operating and design parameters are obtained using the proposed shortcut procedure that is given in Figure 3. The design begins by using eq 4 to determine $\beta$ (i.e., the fraction of intermediate component $\mathrm{B}$ that is sent to the top of prefractionator). The value of $\beta$ is necessary to calculate the minimum vapor flows in the prefractionator, and then minimum vapor flows in each section of main column are obtained using eq 10 . The minimum reflux ratios are calculated, and the actual reflux ratio is set to define the liquid and vapor splits (i.e., $S_{\mathrm{L}}$ and $S_{\mathrm{V}}$, respectively). Solving eqs 18 and 19 provides a way to estimate the number of stages of each section of the main column and the prefractionator. $S_{\mathrm{L}}$ and $S_{\mathrm{V}}$ values are chosen so that there are the same number of trays in section 2 and section 4. The minimum number of trays of the prefractionator and the main column are computed from feed and product compositions. The results of operating and design parameters for the three cases are summarized in Table 3.

Table 3. Operating Parameters of Three Illustrated Cases Obtained Via the Shortcut Method

\begin{tabular}{|c|c|c|c|}
\hline & Case 1 & Case 2 & Case 3 \\
\hline parameter & $\begin{array}{c}\text { pentane/hexane/ } \\
\text { heptane }\end{array}$ & $\begin{array}{c}\text { benzene/toluene/ } \\
\text { xylene }\end{array}$ & $\begin{array}{c}\text { ethanol/propanol/ } \\
\text { butanol }\end{array}$ \\
\hline$\beta$ & 0.575 & 0.610 & 0.630 \\
\hline$S_{\mathrm{L}}$ & 0.528 & 0.432 & 0.254 \\
\hline$S_{\mathrm{V}}$ & 0.746 & 0.7434 & 0.5426 \\
\hline$R_{\min }$ & 1.219 & 2.535 & 6.257 \\
\hline$R$ & 2.44 & 2.84 & 8.13 \\
\hline$\varphi$ & 3.44 & 2.90 & 9.615 \\
\hline$N_{\text {main column }}$ & 27 & 40 & 37 \\
\hline$N_{\text {rectif }}$ & 8 & 12 & 9 \\
\hline$N_{\text {stripp }}$ & 9 & 12 & 8 \\
\hline$N_{\text {prefractionator }}$ & 10 & 17 & 20 \\
\hline$N_{\mathrm{F}}$ & 5 & 8 & 16 \\
\hline$N_{\text {sidestream }}$ & 13 & 22 & 20 \\
\hline$L_{2} / V_{2}$ & $23.18 / 46.17$ & $1338 / 3113.65$ & $41.32 / 99.12$ \\
\hline
\end{tabular}

For the separation of selected ternary mixture cases, the obtained values of $\beta$ show that the intermediate components are almost fairly well-distributed between the top and the bottom of the prefractionator, and the difference between the volatilities of intermediate and light components is only slightly higher than those of the intermediate and heavy components. It could also be observed from Table 3 that the vapor split ratios are higher than the liquid split ratios for the three mixtures, namely, the amounts of vapor going to the prefractionator are more important than those of the liquid. This is due to the fact that the prefractionator holds a sufficient amount of liquid, which is a summation of part of the internal liquid coming from the rectifying section and part coming from the saturated liquid feed mixture. The reflux ratios for Cases 1, 2, and 3 are 2, 1.12, and 1.3 times greater than the minimum reflux ratios, respectively, and they are all located within an acceptable range in industrial practice.

For cases 1 and 2, the ESI values are close to 1, namely, the ease of separation of $\mathrm{B}$ and $\mathrm{C}$ is the same as that of the separation of A and B (ESI = 1). Therefore, the total number of trays of rectifying and stripping sections are approximately the same. The intermediate component (B) is distributed between the top and bottom products of the prefractionator; therefore, separation of the light component (A) from the heavy component (C) takes place in the prefractionator. Consequently, the prefractionator required more stages to obtain the expected purities of $\mathrm{A}$ as the top product in section 1, while $\mathrm{C}$ is the bottom product in section 3. For case 3, the separation between ethanol and propanol is more difficult than that between propanol and butanol, since the ESI value is $<1$. Therefore, the separation requires a larger total number of stages and a higher reflux ratio than the two previous mixtures. The results are less influenced by the values of the liquid split ratio $\left(S_{\mathrm{L}}\right)$ and the vapor split ratio $\left(S_{\mathrm{V}}\right)$ than those for the two other cases, since Case 3 has higher of reflux ratio and reboiler ratio values. The interlinking liquid and vapor compositions are estimated by combining the feed line and the operating line. Equations 27 and 28 provide an estimation of the interlinking streams, as a function of the reflux ratio and thermal feed state of each feed section.

$$
\begin{aligned}
& x_{i, L_{2}}=\frac{\mathrm{x}_{i, \mathrm{D} 2}\left(R_{1}+1\right)+x_{i, \mathrm{D} 1}(q-1)}{R_{1}+q} \quad i=\{\mathrm{A}, \mathrm{B}, \mathrm{C}\} \\
& y_{i, V_{2}}=\frac{R_{1} x_{i, \mathrm{D} 2}+q x_{i, \mathrm{D} 1}}{R_{1}+q} \quad i=\{\mathrm{A}, \mathrm{B}, \mathrm{C}\}
\end{aligned}
$$

Accordingly, the calculated interlinking liquid and vapor compositions between the prefractionator and the main column are shown in Table 4, which are necessary design parameters for further rigorous simulations.

4.2. Rigorous Simulation of DWC. To complete the process design, further rigorous simulation is carried out using the ProSim Plus process simulator. ${ }^{45}$ In the first step of the rigorous simulation, the preliminary design parameters of DWC provided by the shortcut method in section 4.1 are first validated by rigorous simulation.

The corresponding results are summarized in Table 5. We notice that the rigorous simulation leads to approximately the same product specifications as those imposed as constraints in the applied shortcut method. There are small differences between the purities of the three products assumed in the shortcut method and obtained by the rigorous simulation. For the three illustrated cases, the compositions of the light component in the distillate are very close to the specified compositions in the preliminary design, and both compositions

Table 4. Interlinking Liquid and Vapor Compositions between the Prefractionator and the Main Column, Using Shortcut

\begin{tabular}{|c|c|c|c|}
\hline & Case 1 & Case 2 & Case 3 \\
\hline stream & pentane/hexane/heptane & benzene/toluene/xylene & ethanol/propanol/butanol \\
\hline liquid, $\mathrm{L}_{2} x_{\mathrm{iL2} 2}$ (mole fraction) & $0.6275 / 0.3659 / 0.0066$ & $0.3193 / 0.6407 / 0.04$ & $0.1919 / 0.7953 / 0.0128$ \\
\hline vapor, $\bar{V}_{2} y_{\mathrm{iV} 2}$ (mole fraction) & $0.0558 / 0.7683 / 0.1759$ & $0.0 / 0.6351 / 0.3649$ & $0.0 / 0.8390 / 0.161$ \\
\hline
\end{tabular}
Method Parameters 
Table 5. Validation of Shortcut Design Parameters by Rigorous Simulation

\begin{tabular}{|c|c|c|c|}
\hline \multirow[b]{2}{*}{ specifications } & \multirow{2}{*}{$\frac{\text { Case } 1}{\text { pentane/hexane/heptane }}$} & \multirow{2}{*}{$\frac{\text { Case } 2}{\text { benzene/toluene/xylene }}$} & \multirow{2}{*}{$\frac{\text { Case } 3}{\text { ethanol/propanol/butanol }}$} \\
\hline & & & \\
\hline \multicolumn{4}{|l|}{ Distillate } \\
\hline$x_{\mathrm{D} 1}($ mole fraction $)$ & $0.9761 / 0.0239 / 0$ & $0.9876 / 0.0124 / 0$ & $0.9553 / 0.0447 / 0$ \\
\hline \multicolumn{4}{|l|}{ Sidestream } \\
\hline$S(\mathrm{kmol} / \mathrm{h})$ & 9 & 1065.6 & 60 \\
\hline \multicolumn{4}{|l|}{ Bottom Product } \\
\hline$W_{3}(\mathrm{kmol} / \mathrm{h})$ & 18 & 1443.6 & 20 \\
\hline$x_{\mathrm{W} 3}($ mole fraction $)$ & $0 / 0.0302 / 0.9698$ & $0 / 0.046 / 0.954$ & $0 / 0.0431 / 0.9569$ \\
\hline \multicolumn{4}{|l|}{ Vapor } \\
\hline$V_{3}(\mathrm{kmol} / \mathrm{h})$ & 54.45 & 3881.6 & 99 \\
\hline \multicolumn{4}{|l|}{ Duty } \\
\hline$Q_{R}(\mathrm{~kJ} / \mathrm{h})$ & $1.699 \times 10^{6}$ & $1.587 \times 10^{8}$ & $7.139 \times 10^{6}$ \\
\hline
\end{tabular}

Table 6. Interlinking Liquid and Vapor Compositions between the Prefractionator and the Main Column, Using Rigorous Simulation

\begin{tabular}{cccc} 
& Case 1 & Case 2 & Case 3 \\
\cline { 2 - 2 } stream & pentane/hexane/heptane & benzene/toluene/xylene & ethanol/propanol/butanol \\
liquid, $L_{2} x_{\mathrm{iL} 2}$ (mole fraction) & $0.4074 / 0.5739 / 0.0187$ & $0.127 / 0.8176 / 0.0553$ \\
vapor, $V_{2} y_{\mathrm{iV} 2}$ (mole fraction) & $0.012 / 0.7113 / 0.2766$ & $0.0002 / 0.8127 / 0.1871$ & $0.0084 / 0.8196 / 0.1710$ \\
\hline
\end{tabular}

Table 7. Design Parameters of the DWC Column, Using Rigorous Simulation for High Product Purities

\begin{tabular}{|c|c|c|c|}
\hline \multirow[b]{2}{*}{ specifications } & \multicolumn{3}{|c|}{ Values } \\
\hline & pentane/hexane/heptanes & benzene/toluene/xylene & ethanol/propanol/butanol \\
\hline \multicolumn{4}{|l|}{ Distillate } \\
\hline$D_{1}(\mathrm{kmol} / \mathrm{h})$ & 18 & 1090.8 & 20 \\
\hline$x_{\mathrm{D} 1}($ mole fraction $)$ & $0.99 / 0.01 / 0$ & $0.99 / 0.01 / 0$ & $0.963 / 0.037 / 0$ \\
\hline \multicolumn{4}{|l|}{ Sidestream } \\
\hline$S(\mathrm{kmol} / \mathrm{h})$ & 9 & 1065.6 & 60 \\
\hline \multicolumn{4}{|l|}{ Bottom Product } \\
\hline$W_{3}(\mathrm{kmol} / \mathrm{h})$ & 18 & 1443.6 & 20 \\
\hline$x_{\mathrm{W} 3}($ mole fraction $)$ & 0/0.0048/0.9952 & 0/0.0105/0.9895 & $0 / 0.016 / 0.984$ \\
\hline \multicolumn{4}{|l|}{ Vapor } \\
\hline$V_{3}(\mathrm{kmol} / \mathrm{h})$ & 56.62 & 3881.6 & 192.3 \\
\hline \multicolumn{4}{|l|}{ Heat Duty } \\
\hline$Q_{\mathrm{R}}(\mathrm{kJ} / \mathrm{h})$ & $1.696 \times 10^{6}$ & $1.586 \times 10^{8}$ & $7.139 \times 10^{6}$ \\
\hline$\beta$ & 0.348 & 0.636 & 0.57954 \\
\hline$S_{\mathrm{L}}$ & 0.49335 & 0.391 & 0.2075 \\
\hline$S_{\mathrm{V}}$ & 0.7771 & 0.549 & 0.442 \\
\hline$R$ & 2.59 & 2.84 & 8.13 \\
\hline$\varphi$ & 3.111 & 2.9 & 9.615 \\
\hline$N_{\text {main column }}$ & 50 & 45 & 62 \\
\hline$N_{\text {rectif }}$ & 4 & 10 & 18 \\
\hline$N_{\text {stripp }}$ & 9 & 12 & 16 \\
\hline$N_{\text {prefractionator }}$ & 37 & 23 & 28 \\
\hline$N_{\mathrm{F}}$ & 18 & 10 & 14 \\
\hline$N_{\text {sidestream }}$ & 25 & 21 & 24 \\
\hline
\end{tabular}

of the heavy component in the bottom product and the intermediate component in the sidestream product are just slightly higher than that in the design specifications. Thus, we confirmed that the assumptions assumed previously in the shortcut method are verified by rigorous simulation. As can also be observed in Table 5, the top product is almost free of heavy component $\mathrm{C}$, the bottom product is almost free of light component $\mathrm{A}$, and the intermediate component is distributed in the three products. Note that the compositions of the interlinking of liquid and vapor streams to the prefractionator obtained from rigorous simulation are similar to those obtained 


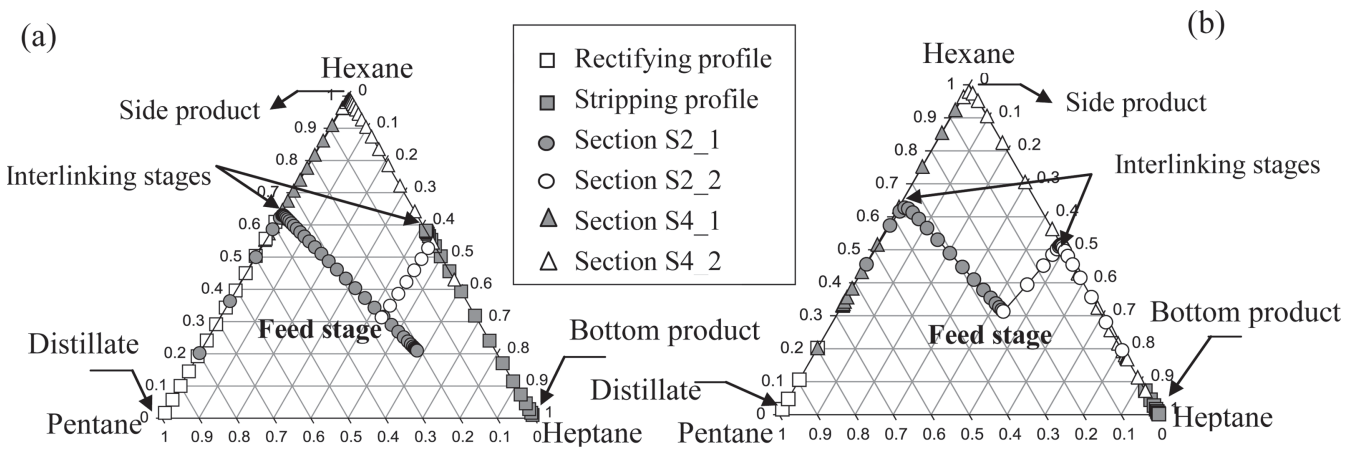

Figure 4. Composition profiles of pentane-hexane-heptane in the DWC column: (a) using differential equations and (b) using rigorous simulation.

(a)

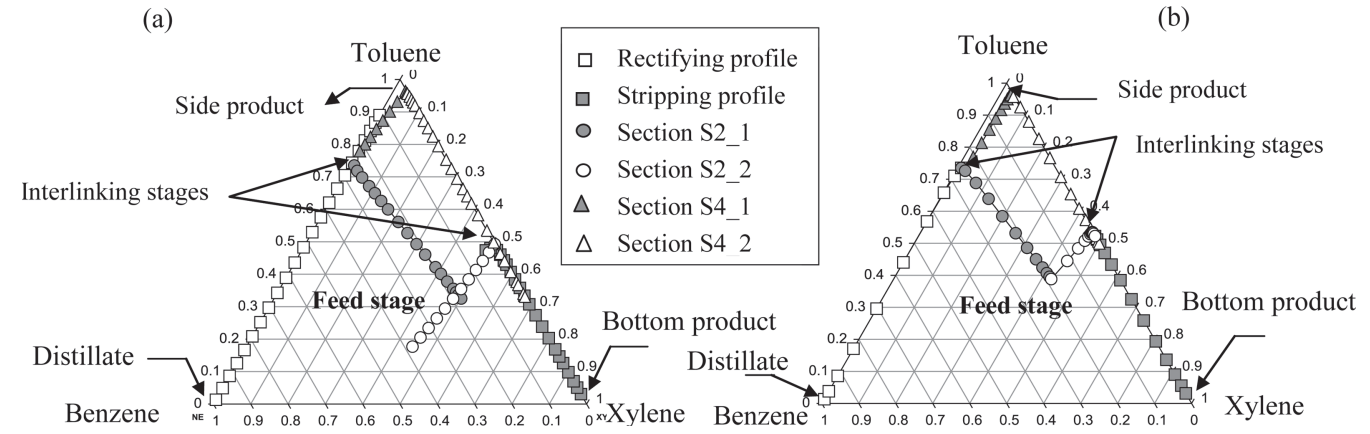

Figure 5. Composition profiles of benzene-toluene-xylene in DWC column: (a) using differential equations and (b) using rigorous simulation.

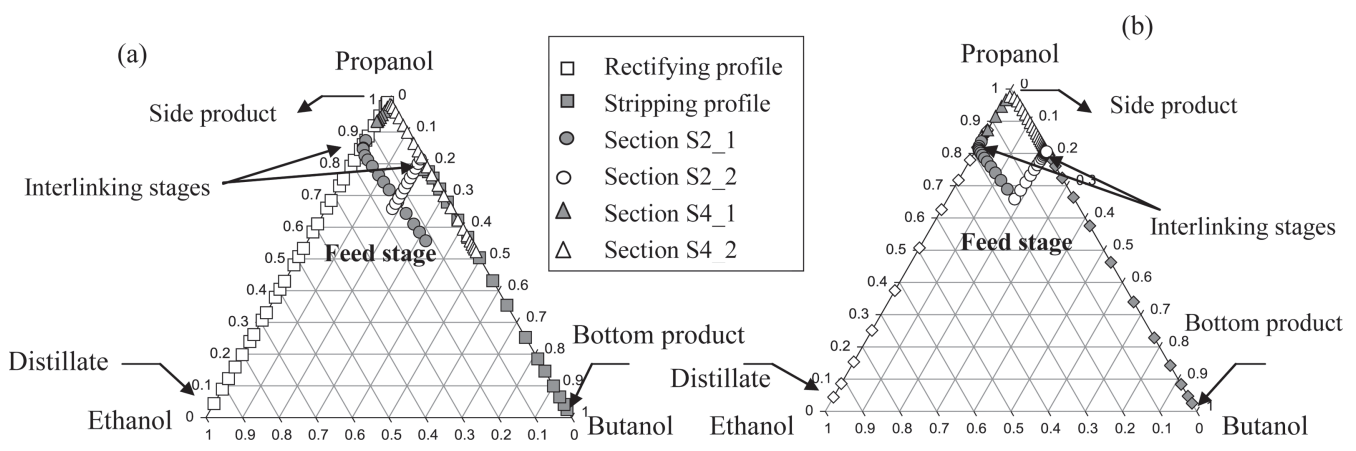

Figure 6. Composition profiles of ethanol-propanol-butanol in DWC column: (a) using differential equations and (b) using rigorous simulation.

by the shortcut method as well (see Table 6), which validate the efficiency of the applied method.

In the second step of rigorous simulation, the simulations have been carried out to improve the operating parameters obtained from the shortcut method to reach high purities (99\% mole fraction) of the three products. To validate the proposed design method, rigorous simulations are performed by first determining the operating conditions (such as liquid and vapor splits ratios), and then the design parameters of DWC (namely, the number of stages in each column section, feed stage, upper and lower interlinking stages, and side product draw stage). To establish the effects of changes in internal flows to the design equations, operating conditions (i.e., liquid and vapor splits ratios and reflux ratio) that could result in different internal flows in all column sections are used to calculate their corresponding numbers of equilibrium stages. The design procedure was repeated for different systems to test the usefulness and efficiency of our method.

This step of the design method gives near-optimal values of all important design variables, mainly, the number of trays in all column sections (prefractionator and main column) and values of the interconnecting streams. The achieved specifications of the three products in DWCs using improved design parameters are listed in Table 7.

The obtained results show that the purities of the three products are influenced by key parameters: the liquid and vapor split ratio values. To obtain a high purity of each product (>98\%), compared to case 3 with ESI $<1$, the separation of Case 1 and Case 2 with ESI $>1$ requires a greater total number of stages. Therefore, to get the desired purities, the total number of main column stages must be increased to maintain a constant reflux ratio. For the three illustrated cases, the separation requires more stages in the prefractionator and the intermediate section than those in the rectifying and stripping sections.

4.3. Composition Profiles of the DWC. The composition profiles for the three ternary mixtures cases are displayed in Figures 4-6. The obtained profiles based on differential equations show that the profiles of main column and prefractionator intersect at the locations of feeds and products stages. This means that the preliminary design parameters obtained from the shortcut method are feasible. As shown in 
the Figures 4a, 5a, and 6a, the rectifying profile intersects with the upper section profile of the prefractionator at the interlinking stage location, and the stripping profile connects the lower section of the prefractionator at the interlinking stage location as well. Therefore, the calculated profiles based on differential equations provide a suitable composition of interlinking stages, which are important data for the thermally coupled distillation column structure. For the middle section of the main column, the intersection between the upper and lower section 4 (S4_1 and S4_2) performed at the sidestream stage composition and also joined the rectifying and stripping sections.

The composition profiles of different sections obtained using developed differential equations (i.e., eqs 20-25) based on shortcut design parameters method are in accordance with those calculated using rigorous simulations (see Figures $4 b, 5 b$, and $6 \mathrm{~b})$. From the differential profiles, we notice that the intersection of Sections S2_1 and S2_2 occurs at the composition of the feed stage, and the intersection of Sections S4_1 and S4_2 occurs at the sidestream effluent stage.

The composition of the feed stage obtained from the intersection of composition profiles for the three investigated cases, using both rigorous simulation and differential equations, are given in Table 8 . We note that the feed stage composition

Table 8. Feed Stage Composition of the DWC Column, Using Rigorous Simulation Profiles and Differential Equations Profiles

\begin{tabular}{lcc}
\multicolumn{1}{c}{ system } & rigorous simulation & $\begin{array}{c}\text { differential equation } \\
\text { profiles }\end{array}$ \\
\hline pentane/hexane/heptane & $0.254 / 0.313 / 0.433$ & $0.26 / 0.32 / 0.42$ \\
benzene/toluene/xylene & $0.186 / 0.387 / 0.427$ & $0.18 / 0.34 / 0.48$ \\
$\begin{array}{l}\text { ethanol/propanol/ } \\
\text { butanol }\end{array}$ & $0.161 / 0.659 / 0.18$ & $0.14 / 0.67 / 0.19$ \\
\hline
\end{tabular}

of the DWC column deduced from the intersection of the differential profiles method are very close to those obtained via the rigorous simulation method (see Table 8). This means that the novel proposed method works well for finding feasible operating parameters and is close to the best design of the DWC.

\section{CONCLUSIONS}

This work provides a novel method that can be used for the design of dividing-wall columns (DWCs); this method is based on shortcut and differential equation profile methods. For the separation of non-azeotropic mixtures, an efficient model is developed to define preliminary design parameters. Three case studies of non-azeotropic systems are considered to validate this method. It can be observed from the result that the key parameters-the liquid and vapor split ratios-play a very important role in the design of DWCs. The method provided feasible design parameters of the distillation column with an internal separating wall, which can be used for the initialization of a rigorous simulation.

The developed differential equations allow one to examine the feasibility of the preliminary design parameters, defined from the applied shortcut method, and determining the composition of feed and side product at the intersection of the plotted profiles of DWCs. We conclude that the differential equations method is consistent with the shortcut method, and the two methods are also validated by rigorous simulation. The
DWC configurations for distillation columns are not only technically feasible but also economically more attractive, with significant energy savings.

Note that many degrees of freedom of input and output exist; thus, the complex nonideal DWC separation provides difficulties for steady-state design. In this study, shortcut and composition profile methods are proposed for design feasible parameters of the DWC process; it provides the necessary initial key operating parameter values for optimization and dynamic studies.

\section{AUTHOR INFORMATION}

\section{Corresponding Authors}

*(W.S.) E-mail: snweifeng@gmail.com.

*(S.W.) E-mail: wsacn@163.com.

\section{Notes}

The authors declare no competing financial interest.

\section{NOMENCLATURE}

$\alpha_{i j}=$ relative volatility of component $i$, with respect to component $j$

$\beta=$ fraction of $\mathrm{B}$ sent to the top of the prefractionator

$\varphi=$ boilup ratio

$D_{k}=$ top product flow rate of section $k$

$F=$ feed flow rate

$W_{k}=$ bottom product flow rate of column $i$

$L_{k}=$ liquid flow in the upper zone of column $i$

$L_{\text {min }, k}=$ minimum liquid flow in the upper zone of column $i$

$\bar{L}_{k}=$ liquid flow in the lower zone of column $i$

$\bar{L}_{\min , k}=$ minimum liquid flow in the lower zone of column $i$

$N_{k}=$ total number of trays of section $i$

$N_{\text {min }, k}=$ minimum total number of trays of section $i$

$N_{\text {Total }}=$ total number of trays

$q=$ thermal feed state

$R_{k}=$ reflux ratio of section $k$

$R_{\text {min }, k}=$ minimum reflux ratio of section $k$

$S=$ side-draw flow rate

$S_{\mathrm{L}}=$ liquid split ratio

$S_{\mathrm{V}}=$ vapor split ratio

$V_{i}=$ vapor flow in the upper zone of section $i$

$V_{\min , i}=$ minimum vapor flow in the upper zone of section $i$

$\bar{V}_{i}=$ vapor flow in the lower zone of section $i$

$\bar{V}_{\text {min, } i}=$ minimum vapor flow in the lower zone of section $i$

$x_{i, j}=$ mole fraction of component $i$ in liquid flow $j$

$Z_{i}=$ mole fraction of component $i$ in the feed flow

$\theta=$ root of Underwood's equation

$N_{\text {main column }}=$ total number of stages in the main column

$N_{\text {rectif }}=$ number of stages in the rectifying section

$N_{\text {stripp }}=$ number of stages in the stripping section

$N_{\text {prefractionator }}=$ total number of stages in the prefractionator

$N_{\mathrm{F}}=$ number of feed stages

$N_{\text {sidestream }}=$ number of sidestream stages

\section{REFERENCES}

(1) Hewitt, G.; Quarini, J.; Morrell, M. More efficient distillation. Chem. Eng. 1999, 16-19.

(2) Ignat, R.; Woinaroschy, A. Dynamic analysis and controllability of dividing wall distillation columns. Chem. Eng. Trans. 2011, 25, 647652.

(3) Premkumar, R; Rangaiah, G. Retrofitting conventional column systems to dividing-wall columns. Chem. Eng. Res. Des. 2009, 87, 4760. 
(4) Dwivedi, D.; Halvorsen, I. J.; Skogestad, S. Control structure selection for three-product Petlyuk (dividing wall) column. Chem. Eng. Process. 2013, 64, 57-67.

(5) Dejanovic, I.; Matijăsevic, L. J.; Olujic, Z. An effective method for establishing the stage and reflux requirement of three-product dividing wall columns. Chem. Biochem. Eng. Q. 2011, 25, 147-157.

(6) Dejanovic, I.; Matijăsevic, L. J.; Halvorsen, I. J.; Kogestad, S.; Jansen, H.; Kaibel, B. Designing four-product dividing wall columns for separation of a multicomponent aromatics mixture. Chem. Eng. Res. Des. 2011, 89, 1155-1167.

(7) Dejanovic, I.; Matijăsevic, L. J.; Olujic, Z. Dividing wall columnA breakthrough towards sustainable distilling. Chem. Eng. Process. 2011, 49, 559-580.

(8) Diggelen, R. C. V.; Kiss, A. A.; Heemink, A. W. Comparison of control strategies for dividing-wall columns. Ind. Eng. Chem. Res. 2010, 49 (2), 288-307.

(9) Kiss, A. A.; Rewarad, R. R. Energy efficient control of a BTX dividing-wall column. Comput. Chem. Eng. 2011, 35, 2896-2904.

(10) Errico, M.; Tola, G.; Rong, B. G.; Demurtas, D.; Turunen, I. Energy saving and capital cost evaluation in distillation column sequences with a divided wall column. Chem. Eng. Res. Des. 2009, 87 (12), 1649-1657.

(11) Kiss, A. A.; Bildea, C. S. A control perspective on process intensification in dividing-wall columns. Chem. Eng. Process. 2011, 50 (3), 281-292

(12) Lee, S. H.; Shamsuzzoha, M.; Han, M.; Kim, Y. H.; Lee, M. Y. Study of structural characteristics of a divided wall column using the sloppy distillation arrangement. Korean J. Chem. Eng. 2011, 28 (2), $348-356$

(13) Segovia-Hernandez, J. G.; Hernandez-Vargasa, E. A.; MarquezMũnoz, J. A. Control properties of thermally coupled distillation sequences for different operating conditions. Comput. Chem. Eng. 2007, 31 (7), 867-874.

(14) Yildirim, O.; Kiss, A. A.; Kenig, E. Y. Dividing wall columns in chemical process industry: a review on current activities. Sep. Purif. Technol. 2011, 80, 403.

(15) Sangal, V. K.; Kumar, V.; Mishra, I. M. Optimization of structural and operational variables for energy efficiency of a divided wall distillation column. Comput. Chem. Eng. 2012, 40, 33-40.

(16) Halvorsen, I. J.; Dejanovic, I.; Skogestad, S.; Olujic, Z. Internal configurations for multi-product dividing wall column. Chem. Eng. Res. Des. 2013, 91 (10), 1954-1965.

(17) Nguyen, V. D.; Lee, M. Improvement of deethanizing and depropanizing fractionation steps in NGL recovery process using dividing wall column. J. Chem. Eng. Jpn. 2012, 45 (4), 285-294.

(18) Sangal, V. K.; Kumar, V.; Mishra, I. M. Process parametric optimization of a divided wall distillation column. Chem. Eng. Commun. 2014, 201, 72-87.

(19) Wright, R. O. Fractionation Apparatus, U.S. Patent No. 2,471,134, 1949.

(20) Petyluk, F. B.; Platonov, V. M.; Slavinskii, D. M. Thermodynamically optimal method of separating multicomponent mixtures. Int. Chem. Eng. 1965, 5 (3), 555-561.

(21) Amminudin, K. A.; Smith, R.; Thong, D. Y. C.; Towler, G. P. Design and optimization of fully thermally coupled distillation columns, Part 1: Preliminary design and optimization methodology. Trans. Inst. Chem. Eng. 2001, 79, 701-715.

(22) Fidkowski, Z.; Krolikowski, L. Minimum energy requirements for thermally coupled distillation systems. AIChE J. 1987, 33, 643653.

(23) Triantafyllou, C.; Smith, R. The design and optimization of fully thermally coupled distillation columns. Trans. Inst. Chem. Eng., Part A 1992, 70, 118-132.

(24) Agrawal, R; Fidkowski, Z. T. Are thermally coupled distillation columns always thermodynamically more efficient for ternary distillation? Ind. Eng. Chem. Res. 1998, 37, 3444-3454.

(25) Abdul Mutalib, M. I.; Smith, R. Operation and control of dividing wall distillation columns, Part 1: Degrees of freedom and dynamic simulation. Trans. Inst. Chem. Eng., Part A 1998, 76, 308-318.
(26) Abdul Mutalib, M. I.; Smith, R. Operation and control of dividing wall distillation columns, Part 2: Simulation and pilot plant studies using temperature control. Trans. Inst. Chem. Eng., Part A 1998, 76, 319-334.

(27) Lee, S. H.; Shamsuzzoha, M.; Han, M.; Kim, H. Y. Study of the structural characteristics of a divided wall column using the sloppy distillation arrangement. Korean J. Chem. Eng. 2011, 28, 348-356.

(28) Uwitonze, H.; Han, S.; Hwang, K. S. New design method for thermally coupled distillation column using group and approximate methods. Ind. Eng. Chem. Res. 2014, 53, 11979-11988.

(29) Uwitonze, H.; Han, S.; Hwang, K. S. Structural design of fully thermally coupled distillation column using approximate group methods. Chem. Eng. Process. 2014, 85, 155-167.

(30) Sotudeh, N.; Sharaki, B. H. Extension of a method for the design of divided wall columns. Chem. Eng. Technol. 2008, 31 (1), 83-86.

(31) Gadalla, M.; Jobson, M.; Smith, R. Shortcut models for retrofit design of distillation columns. Trans. Inst. Chem. Eng. 2003, 81, 971986.

(32) Ramirez-Corrona, N.; Castro-Aguero, A.; Jimènez-Gutierrez, A. Shortcut design of fully thermally coupled distillation systems with postfractionator. Ind. Eng. Chem. Res. 2011, 50, 6282-6296.

(33) Ramirez-Corrona, N.; Jimènez-Gutierrez, A.; Castro-Aguero, A.; Rico-Ramirez, V. Optimum design of Petlyuk and divided wall distillation systems using a shortcut model. Chem. Eng. Res. Des. 2010, $88,1405-1418$

(34) Chu, K. T.; Cadoret, L.; Yu, C. C.; Ward, J. D. A new shortcut design method and economic analysis of divided wall columns. Ind. Eng. Chem. Res. 2011, 50, 9221-9235.

(35) Halvonsen, I. J.; Skogestad, S. Shortcut analysis of optimal operation of Petlyuk distillation. Ind. Eng. Chem. Res. 2004, 43, 39943999.

(36) Agrawal, R.; Fidkowski, Z. T. New thermally coupled schemes for ternary distillation. AIChE J. 1999, 45, 485-496.

(37) Kim, Y. H. A new fully thermally coupled distillation column with postfractionator. Chem. Eng. Process. 2006, 45, 254-263.

(38) Dejanovic, I.; Matijasevic, L. J.; Jansen, H.; C. Z. Oluji, C. Z. Designing a packed dividing wall column for an aromatics processing plant. Ind. Eng. Chem. Res. 2011, 50, 5680-5692.

(39) Fenske, M. R. Fractionation of straight-run Pennsylvania gasoline. Ind. Eng. Chem. 1932, 482-485.

(40) Underwood, A. J. V. Fractional distillation of multicomponent mixtures. Chem. Eng. Progr. 1948, 44, 603.

(41) Gilliland, E. R. Multicomponent rectification: Estimation of the number of theoretical plates as a function of the reflux ratio. Ind. Eng. Chem. 1940, 32, 1220.

(42) Kirkbride, C. G. Process design procedure for multicomponent fractionators. Pet. Ref. 1944, 23, 87.

(43) Lelkes, Z.; Lang, P.; Benadda, B.; Moszkowicz, P. Feasibility of extractive distillation in a batch rectifier. AIChE J. 1998, 44, 810-822.

(44) Lang, P.; Modla, G.; Benadda, B.; Lelkes, Z. Homoazeotropic distillation of maximum azeotropes in a batch rectifier with continuous entrainer feeding. I. Feasibility studies. Comput. Chem. Eng. 2000, 24, $1665-1671$

(45) Lang, P.; Modla, G.; Kotai, B.; Lelkes, Z.; Moszkowicz, P. Homoazeotropic distillation of maximum azeotropes in batch rectifier with continuous entrainer feeding. II. Rigorous simulation results. Comput. Chem. Eng. 2000, 24, 1429-1435.

(46) Shen, W. F. Extension of thermodynamic insights on batch extractive distillation to continuous operation. Ph.D. Thesis, Institut National Polytechnique de Toulouse, Toulouse, France, 2012.

(47) Shen, W. F.; Benyounes, H.; Gerbaud, V. Extension of thermodynamic insights on batch extractive distillation to continuous operation. 1. Azeotropic mixtures with a heavy entrainer. Ind. Eng. Chem. Res. 2013, 52, 4606-4622.

(48) Shen, W. F.; Gerbaud, V. Extension of thermodynamic insights on batch extractive distillation to continuous operation. 2. Azeotropic mixtures with a light entrainer. Ind. Eng. Chem. Res. 2013, 52, 46234637. 
(49) ProsimPlus 3.1: ProSim Ternary Diagram; ProSim: Labege Cedex, France; user guide available at http://www.prosim.net, 2009 (last accessed Feb. 2012).

(50) Tedder, D. W.; Rudd, D. F. Parametric studies in industrial distillation: Part I. Design comparisons. AIChE J. 1978, 24, 303-315. 